\title{
Clues to remind leukemia in patients with arthritis: case presentations
}

\author{
B Makay*, Y Topçu, S Yilmaz and E Unsal
}

Address: Dokuz Eylul University Hospital, Izmir, Turkey

* Corresponding author

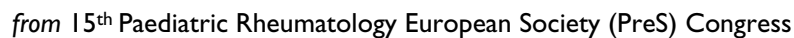

London, UK. 14-17 September 2008

Published: 15 September 2008

Pediatric Rheumatology 2008, 6(SuppI I):PI72 doi:10.II86/I546-0096-6-SI-PI72

This abstract is available from: http://www.ped-rheum.com/content/6/SI/PI72

(C) 2008 Makay et al; licensee BioMed Central Ltd.

Acute lymphocytic leukemia (ALL) may initially present with musculoskeletal symptoms such as pain or swelling, even before appearance of blasts in the peripheral blood. Fifteen to $30 \%$ of all ALL patients have musculoskeletal complaints at disease onset. Such presentation may lead to misdiagnosis of the patients causing a delay in proper management. Here, we present 5 patients who were referred to Pediatric Rheumatology Department for the evaluation of arthritis and were finally diagnosed as ALL (table 1).

The peripheral blood changes were absent or subtle in these patients. Some clinical, laboratory, and radiological clues helped to establish the diagnosis of ALL. We aimed to discuss the usefulness of history, physical findings, and simple laboratory and radiographic tests in decision-making.

Table I: Five patients who were referred to Pediatric Rheumatology Department for the evalution of arthritis and were finall diagnosed as ALL

\begin{tabular}{llll}
\hline Patient & Presentation & Provisional diagnosis & Final diagnosis \\
\hline $10 y, 0^{7}$ & Migratory arthritis, fatigue & Acute rheumatic fever & ALL \\
$3 y, 0^{7}$ & Fever, arthritis of the left hip & Septic arthritis & ALL \\
$2 y,+$ & Arthritis of the right hip & Transient synovitis & ALL \\
$3 y, 0^{7}$ & Pain in legs, inability to walk & JIA & ALL \\
$6 y,+$ & Arthritis of the left elbow, fatigue & Postviral arthritis & ALL
\end{tabular}

